Original article

\title{
OUTPATIENT AND HOME PARENTERAL ANTIBIOTIC THERAPY (OHPAT) IN LOW-RISK FEBRILE NEUTROPENIA: CONSENSUS STATEMENT OF A BELGIAN PANEL
}

\author{
Y. Beguin ${ }^{1}$, Y. Benoit ${ }^{2}$, F. Crokaert ${ }^{3}$, D. Selleslag ${ }^{4}$, B. Vandercam ${ }^{5}$
}

Keywords: Outpatient intravenous antibiotics, febrile neutropenia, low-risk

\begin{abstract}
Febrile neutropenia requires adequate antibiotic treatment. A subgroup of patients are only at low risk for complications and could be treated at home/as outpatients (OHPAT) after a short initial admission for work up. This position paper by a Belgian panel of experts presents criteria defining low-risk in febrile neutropenia, gives an overview of the existing experience and examines the present obstacles to a more widespread use of OHPAT in this country.
\end{abstract}

\footnotetext{
${ }^{1}$ University of Liège, CHU Sart-Tilman, Liège

${ }^{2}$ University of Gent, UZ Gent, Gent

${ }^{3}$ Free University of Brussels, Institut Bordet, Bruxelles

${ }^{4}$ AZ St Jan, Brugge

${ }^{5}$ Catholic University of Louvain, Cliniques St Luc, Louvain-en-Woluwe
}

Yves Beguin is Research Director of the National Fund for Scientific Research (FNRS, Belgium).

Address for correspondence:

Yves Beguin, MD

University of Liège

Department of Hematology

CHU Sart Tilman

4000 Liège

Belgium

Tel +32 - 4 - 3667201

Fax +32 - $4-3668855$

E-mail: yves.beguin@chu.ulg.ac.be

\section{INTRODUCTION}

A panel of Belgian experts, has examined the feasibility of OHPAT in febrile neutropenia in this country. An introductory document, reviewing the history of and summarizing the available clinical experience with ambulatory antibiotic administration in febrile neutropenia and other indications was prepared by an independent copy-writer. Panel participants reviewed this text and three meetings were subsequently held (April $19^{\text {th }} 1999$, October $18^{\text {th }} 1999$ and April $3^{\text {rd }} 2000$ ), during which the various aspects of the subject were extensively discussed. Audio tapes served as a basis for the minutes and additional literature references were gathered. Thereafter, a draft manuscript was prepared, and reviewed several times by all participants independently, under the guidance of one of the authors (Y.B.). The project was supported by Aventis Pharma. The present document summarizes the pro's and con's of this approach, and examines the various problems in the present situation, from an organizational, legal and financial point of view.

Over 30 years ago, Bodey (1) recognized that most neutropenic patients experience febrile episodes during anticancer chemotherapy, especially for those having prolonged and/or pronounced neutropenia (WBC count $<500 / \mathrm{mm}^{3}$ ). Clinical signs alone, however, do not always enable us to distinguish between life-threatening bacteremic episodes and other less severe infections, or even non-infectious conditions (2). Since mortality is increased when antibiotic treatment is delayed (3) - death rate reaching $80 \%$ in Gram-negative sepsis, for instance - it has become common practice to start broad spectrum antibiotics empirically at the onset of fever, mostly as an association of several parenteral compounds but 
also as broad-spectrum monotherapy.

In many western countries, budgetary restrictions impose severe cuts on health expenditures, and one is looking for safe but less expensive approaches to the treatment of many medical problems. Hospital admission as such represents a major burden to the financial envelope. Since twenty years, parenteral antibiotics have occasionally been administered on an outpatient basis. The very first reference to this method has been published in 1974 (4) in cystic fibrosis pediatric patients, whereas the first mention in adults dates back to 1978 (5). Nowadays, OHPAT represents 250,000 patients per year in the US (6).

OHPAT has been widely used to treat bacterial endocarditis (7). These patients mostly need a lengthy hospital stay and clearly benefit from this approach. Their often precarious clinical condition somehow limits the feasibility of this method and most series report the percentage of OHPAT in this disease to be around 5\% (8). As far as glycopeptides are concerned, some experience has been gained with a thrice-a-week or even twice-aweek administration of teicoplanin on an outpatient basis (9). OHPAT offers many advantages in the case of bacterial osteomyelitis or arthritis. Most patients do not require hospitalization because of their general condition, and the prolonged stay is the result of the need for parenteral antibiotics only. A recently published document (10) gives an overview of this topic. Besides these two main indications, OHPAT has been used in the management of community-acquired lower respiratory infections and in cystic fibrosis (11), in the therapy of skin and soft tissue infections (12), in central nervous system infections (13) and in the HIV arena (14).

Oral antibiotherapy has been compared to intravenous antibiotherapy in neutropenic patients receiving anticancer chemotherapy $(15,16)$, but some experience has been gained with OHPAT as well in febrile neutropenia. In 1994, a pilot study on 30 patients concluded that early discharge of low-risk patients on OHPAT is feasible, well received and cost-saving (17). In 1996 and again in $1999(18,19)$, Rolston stated that OHPAT of low-risk patients resulted in a reduction of cost of therapy, better resource utilization and enhanced quality of life. In the pediatric setting, terminally ill patients with malignancies have been treated with OHPAT during febrile episodes (20).

Even though some clinical studies indicate successful outcome with OHPAT, they are either retrospective or of limited size when prospective. Although some studies use a reliable scoring system to assess the real risk (17), this approach is unfortunately not widespread. Yet, it might otherwise allow treatment of a larger proportion of patients, when a subgroup with predictable low-risk becomes clearly defined.

\section{ADVANTAGES AND DRAW-BACKS OF OHPAT}

For the present time, most neutropenic patients with a febrile episode are treated in the hospital setting. This provides opportunities for close monitoring in a safe environment, easy access to intravenous treatment, and fast intervention in case of unforeseen complications. On the other hand, cost of treatment is high and the quality of life is largely impaired. OHPAT offers many advantages, as reported in the prospective studies by Malik. $(21,22)$.

\section{a) Advantages of OHPAT}

\section{Financial savings}

Nowadays, cost-benefit analyses are a difficult endeavor as they should take into account direct cost savings (hospital stay, physician visits, drugs and supplies, childcare, housekeeping, transportation ...) as well as indirect benefits (lost wages, both for patient and family members) (23). In a cohort of 30 patients, attending the day ward of a large London hospital because of chemotherapy courses through central lines, savings up to $3.000 £$ per individual have been found in patients switched to OHPAT in combination with an oral fluoroquinolone, as compared to intravenous hospital treatment with a B-lactam and aminoglycoside combination (24). In another study (25), 5.2\% of patients or $11 \%$ of those receiving antibiotics in a 54 beds unit could benefit from OHPAT. The total cost of intravenous drugs in the classical in-hospital treatment was cheaper by $44 £$ overall, as compared to the ambulatory treatment. But, and this more than compensates for the cost of drugs, 532 hospital days were saved during the study period. Williams (26) showed clear evidence for the cost effectiveness of OHPAT programs.

\section{Decreased prevalence of nosocomial infections}

Keeping patients out of hospital should reduce the prevalence of hospital-acquired infections. Indeed, it has been shown that nosocomial infections affect $5 \%$ of 
hospitalized patients, and increase with every day of stay $(27,28)$. They are a particular threat to granulocytopenic patients. However, this theoretical advantage has not been substantiated yet in patients with neutropenia of short duration.

\section{Improved quality of life $(Q O L)$}

The psychosocial benefit of staying at home is difficult to quantitate. The ability to attend school for children and to resume work for employed adults has been described to be as high as $96 \%$ and $90 \%$, respectively, in one study (29). In the pediatric setting, incentives for keeping children or even infants out of hospital are even stronger (parental occupations, psychological traumatism, school attendance ...). The Parker study (25) also identifies facts perceived as advantages or disadvantages for OHPAT by general practitioners and patients in the United Kingdom (Table 1). Not all of these may apply to the Belgian situation.

\section{b) Adverse effects of OHPAT}

In 1999, a group from Pennsylvania reviewed the medical records of 269 patients (291 courses of treatment) receiving home parenteral antimicrobial therapy (30), scrutinizing the adverse effects. HIV-patients were excluded from the analysis, and the reason for OHPAT was osteomyelitis in 59\% of cases. Taking the different characteristics of this population into account, one notes that the most common side effect of OHPAT was a depression of the WBC count (both leucopenia and neutropenia) and of the platelet count, mostly linked to longterm use of $\beta$-lactams. Further, nephrotoxicity (8\%), diarrhea (7\%) and rash (4\%) were noted. Line complications occurred in $11 \%$ of central catheters and $9 \%$ of the peripheral lines. Overall, admission was needed in $8 \%$ of the patients. Obviously the risks for the patients also depended on the type of complications for which antibiotics were given and not only on line- or drugrelated events. The authors concluded that complications are roughly the same as those expected with inpatients. We are not aware of any such study specifically addressing neutropenic patients.

\section{PROGNOSTIC FACTORS OF INFECTION OUTCOME}

For the above-mentioned reasons, one would like to be able to discharge patients early, after a short admission for work-up and for initiating antimicrobial treatment. One should clearly delineate a "low-risk" group of patients, with criteria easy to apply in daily medical practice.

Table 1: Advantages and disadvantages of OHPAT, as evaluated in the United Kingdom (adapted from (25))

\begin{tabular}{|c|c|c|}
\hline & ADVANTAGES & DISADVANTAGES \\
\hline $\begin{array}{l}\text { TO GENERAL } \\
\text { PRACTITIONER }\end{array}$ & $\begin{array}{l}\text { - saves hospital admissions } \\
\text { - maintains GP responsibility } \\
\text { - makes home management possible } \\
\text { - reduces hospital billing to GP } \\
\text { - speeds up access to hospital }\end{array}$ & $\begin{array}{l}\text { - increased work-load } \\
\text { - concern about safety at home } \\
\text { - costs to GP budget } \\
\text { - distance from hospital } \\
\text { - some loss of responsibility }\end{array}$ \\
\hline TO PATIENT & $\begin{array}{l}\text { - own environment } \\
\text { - no travel for relatives } \\
\text { - quicker improvement } \\
\text { - better contact with GP } \\
\text { - less stress } \\
\text { - happier relatives }\end{array}$ & $\begin{array}{l}\text { - distance from hospital } \\
\text { - lack of nursing care } \\
\text { - worries of relatives } \\
\text { - ill patients should be in hospital } \\
\text { - lack of compliance } \\
\text { - anxiety } \\
\text { - possibility of worse outcome } \\
\text { - infection risk of the IV site }\end{array}$ \\
\hline
\end{tabular}




\section{a) Features of the patient in general}

Over the last few years, various sets of guidelines have been proposed on both sides of the Atlantic, to try to determine in advance which patients could be considered low-risk for complications (17, 31-37). The following criteria seem very important:

- depth of neutropenia: a nadir of neutrophils below 500/ $\mu \mathrm{L}$, and even more so below $100 / \mathrm{mm}^{3}$, is associated with a much increased risk for severe pneumonia and sepsis

- duration of neutropenia: expected duration of 7 to 10 days is often used as cut-off point.

- low monocyte count: monocyte count $<100 / \mu \mathrm{L}$

- hospitalization for other underlying medical problems

- uncontrolled cancer

- type of cancer: solid tumors have a more favorable course than acute leukemias

- type of treatment: maintenance therapy is more favorable than induction chemotherapy. Stem cell or bone marrow transplantation also carries a higher risk. However, Herrmann (38) recently showed that a group of 51 Hodgkin's and non-Hodgkin's lymphoma patients (including high dose chemotherapy and autologous peripheral stem cell transplantation) could effectively be managed at home, and compared well with a group of 88 patients receiving similar treatment in a hospital setting.

- serious comorbidity (heart failure, chronic obstructive pulmonary disease, diabetes, recent surgery) worsens the prognosis

- clinical signs: following signs carry a poor prognosis: hypotension, neurologic changes and alteration of consciousness, dyspnea, abdominal pain, dehydration, bleeding, heart failure or arrhythmias, hepatic or renal failure, extensive cellulitis

\section{b) Characteristics of the infectious process}

After wide clinical use of the first B-lactams, Gramnegative organisms became the first cause of sepsis in neutropenics during the sixties and the seventies. After the introduction of broad spectrum compounds and widespread quinolone prophylaxis, at the turn of the eighties, Gram-positive cocci became more and more important.

At the present time, Gram-positive micro-organisms cause some $60 \%$ of all bacteremias in the neutropenic (39). This might be due to the widespread use of tunneled central venous catheters, fluoroquinolone prophylaxis and to the mucositis accompanying intensive chemo- therapy. This, together with the rise of some fungi (Candida spp. and Aspergillus fumigatus), has had an impact on the empiric choices.

A high number of febrile episodes remains without known cause, even after extensive work-up: $66 \%$ of fevers remain unexplained according to the American National Cancer Institute and the EORTC (2). Fever of unknown origin conveys a worse prognosis in non-neutropenic patients, but this does not seem to be true in febrile neutropenia. (31). However, unspecified infections will often require many changes in antibiotic treatment, in itself a risk factor. Amongst specific infections, uncomplicated urinary tract infections and catheter exit infections have a better prognosis than extensive pneumonia or than infection of the subcutaneous catheter tunnel. The virulence of the micro-organism determines the outcome. For instance, catheter-related bacteremia caused by coagulase-negative staphylococci has a better prognosis than Gram-negative sepsis.

\section{DEFINITION OF LOW-RISK NEUTROPENIA}

In Talcott's paper (32), the risk groups were defined as follows:

- group 1: inpatients at the time of fever appearance

- group 2: outpatients with concurrent comorbidity

- group 3: same as 2 but uncontrolled cancer

- group 4: neutropenic outpatients with fever but without risk factors. The latter was considered "low-risk".

Taking into account the experience detailed above, particularly that of the EORTC and of Talcott, the Multinational Association for Supportive Care in Cancer developed an internationally validated scoring system (36). We summarize here the factors contributing to the risk index in that document:

- absence of symptoms or mild symptoms (5 points) or moderate symptoms (3 points)

- absence of hypotension (5 points)

- absence of chronic pulmonary obstructive disease (4 points)

- solid tumor or absence of previous fungal infection in hematologic patients (4 points)

- absence of dehydration (3 points)

- outpatient status (3 points)

- age younger than 60 years ( 2 points)

A risk-index score $\geq 21$ identified low-risk patients with a specificity of $91 \%$. 
On the other hand, many factors may also prevent discharge:

- allergy to the drugs contemplated for OHPAT

- microbial resistance to contemplated antibiotics

- need for hospitalization for concomitant medical conditions: renal failure, hepatic failure, shock, respiratory failure, bleeding, cardiac failure or arrhythmias, extensive mucositis or cellulitis ...

- need for other IV lines (rehydration, other drugs ...)

- inability to ensure proper hydration and/or to take oral medications

- inadequate reliability and psychosocial environment

- central nervous system infections

- allogeneic stem cell transplantation

- induction chemotherapy

\section{PRACTICAL CONSIDERATIONS}

\section{a) Short admission to hospital for work-up}

Most authors will agree that a short admission (48 hours) is necessary for work-up in neutropenic patients with unexplained fever. It will also enable the physicians to obtain the results of at least some laboratory tests (e.g. blood cultures, expectorations, urine culture) and to initiate antibiotic treatment adequately. During that period, it will be critical to determine the risk category of the patient and to document the origin of infection. Every effort will be made to localize the origin of the fever, all necessary samples will be sent to the microbiology laboratory and antibiotic treatment will be started, largely on an empiric basis. A review from the Infectious Diseases Society of America (35) describes the available options: [1] combination therapy with an aminoglycoside plus either an antipseudomonal penicillin, a $3^{\text {rd }}$ or $4^{\text {th }}$ generation cephalosporin, or a carbapenem; [2] if the use of vancomycin is justified, choose a combination of vancomycin and either an antipseudomonal penicillin, cefepime, ceftazidime or a carbapenem, with or without an aminoglycoside. The attitude will be reassessed if fever persists after 36-72 hours. After that initial work-up phase, low risk patients will possibly be discharged. Some low risk patients may be eligible for oral antibiotics, but this is beyond the scope of this paper.

\section{b) Antibiotics and supportive care}

Broad-spectrum antibiotics suitable for once-a-day intravenous administration belong to three categories:
- aminoglycosides (all the molecules available in Belgium)

- cephalosporins (ceftriaxone in particular)

- glycopeptides (teicoplanin in particular).

As an alternative, molecules with a shorter half-life can be chosen, making use of slow infusion devices. Detailed reviews on the pharmacokinetics of antimicrobial drugs and on infusion devices available for outpatient use have been published $(40,41)$. Most of the times, ceftriaxone will be the treatment of choice. For documented or probable infections with Gram positive cocci, teicoplanin will be the treatment of choice. Duration of treatment will be guided by clinical judgment and recovery from neutropenia, and will usually range from 5 to 8 days.

According to ASCO recommendations (42), there is strong evidence that colony-stimulating factors (CSF) cannot be recommended as routine adjunct therapy for the treatment of uncomplicated fever and neutropenia. Uncomplicated fever and neutropenia are defined as follows : fever $<10$ days in duration; no evidence of pneumonia, cellulitis, abscess, sinusitis, hypotension, multiorgan dysfunction or invasive fungal infections ; and no uncontrolled malignancies. All trials have consistently shown a decrease in the duration of neutropenia $<500 / \mu$ l, but clinical benefit has not consistently accompanied the decreased duration of neutropenia.

\section{c) Potential alternatives for the IV administration}

In any case, the patients and their family will be given a list of useful telephone numbers, and the address of the emergency ward of the hospital in charge, in case of unforeseen complications. These facilities should be accessible 24 hours a day. A new admission will be contemplated in case of reappearance of fever. However, this eventuality seems rather infrequent. Two alternatives are possible for antibiotic administration. General organizational aspects of these alternatives in neutropenic and non-neutropenic patients have been reviewed (43).

\section{On a day clinic basis}

Where no financial intervention from Social Security is available, patients attend the day clinic, on a daily or thrice-a-week basis (9). The nursing team administers the parenteral injection and the physician takes advantage of the patient's presence to check the vital signs and the clinical evolution. In our country, some teams 
occasionally treat individual adult patients with OHPAT (personal communication, Dr. D. Vogelaers, Infectious Disease specialist, University Hospital Ghent and Dr. D. Selleslag, oncologist, AZ St Jan, Brugge). To illustrate this point, we mention the following case report (courtesy of Dr. Selleslag).

A 60 -year-old AML patient in remission was on outpatient maintenance therapy with monthly cycles of low dose cytarabine. He developed fever of $39^{\circ} \mathrm{C}$ when the neutrophil count was 300/ $\mu$ l. There was no sign of infection on clinical examination and blood pressure was normal. Chest X-ray was normal. He was admitted for work-up and was started on empiric antibiotic treatment (ceftazidim and amikacin). After 48 hours, all blood cultures became positive for Staphylococcus epidermidis, susceptible to glycopeptides only. The bacteremia presumably originated from a double lumen Hickman line, although no sign of exit site or tunnel infection was present. The Hickman line was kept in place because of peripheral venous access problems. Treatment was switched to teicoplanin $800 \mathrm{mg} \mathrm{IV/day,} \mathrm{making} \mathrm{use} \mathrm{of}$ another lumen of the catheter every day. The patient became afebrile 72 hours after admission. As he fulfilled the criteria for low-risk neutropenia, he completed treatment for another 7 days at the day clinics. More than 2 months after the last chemotherapy, the Hickman line is still in place, without recurrence of bacteremia. This case report illustrates the feasibility of outpatient treatment with once-a-day antibiotics for coagulase negative Staphylococcus catheter-related bacteremia in patients with low risk neutropenia.

\section{As home treatment}

Practice guidelines for community-based parenteral antibiotherapy have been published (44). In the Netherlands, some teams have accumulated experience with home parenteral antibiotics (45-47). The hospital pharmacy delivers all the needed material (drugs, IV lines, syringes, dressings ...), a financial agreement is reached with Social Security or, alternatively, sponsoring is organized with private funding. In some instances, nurses have been especially trained to educate the patients and perform the first administration at home. In order to be able to achieve home parenteral antibiotics, some practical problems need to be tackled:

- budgetary issues: parenteral antibiotics often cannot claim reimbursement on an out-of-hospital basis, medical advice from the oncologist in charge is often not paid for, community pharmacies are not always able to charge for the necessities.

- organizational issues: the relay between hospital and home care is less than perfect, as far as exchange of medical information is concerned (link between general practitioner and hospital oncologist), but also concerning nursing needs (private home nursing systems or free-lance nursing personnel). Moreover, some drugs or technical devices may not be available for out-of-hospital use.

- qualification issues: the private nurses are not always acquainted with the type of care needed and the general practitioners may be reluctant to take full responsibility for cancer patients, especially acute leukemias. At this point, one must emphasize the importance of trained nurses, able to interact with the hospital and the community health care providers (city nurses, general practitioners, family ...).

\section{EXPERIENCE IN GHENT: THE "KOESTER PROJECT"}

The Koester project (for "Kinder Oncologische Eenheid voor Specifieke Thuiszorg En Rehabilitatie") started in 1990 at the Akademisch Ziekenhuis Ghent under the guidance of Prof. Y Benoit (Pediatric onco-hematologic department) and Dr. G Laureys (Department of Pediatrics). After initial work-up during a short hospital stay for providing precise diagnosis, taking all necessary samples and initiating treatment, most febrile neutropenic patients come into consideration for further home treatment. Of these, a selected (see table 2 for criteria) subgroup is discharged on parenteral antibiotics - either a once-a-day third generation cephalosporin and an aminoglycoside in case of susceptible Gram-negative infection, or a once-a-day glycopeptide for Gram-positive infections, mostly due to methicillin-resistant staphylococci.

The team consists of permanent collaborators available in the hospital and, for home interventions, of pediatricians, oncologists, psychotherapists and 3 specially trained nurses who interact with the home care (physician, community nurses, patient's close relatives). They are reachable 24 hours a day and make very precise instructions available, together with a list of useful telephone numbers (pediatrician in charge, emergency ward of the teaching hospital, general practitioners on call ...). The medicines, as well as all the necessary accessories, such as perfusion kits, needles, dressings are dispatched through the hospital pharmacy. Financial support is provided in part by the association 
Table 2 : Selection criteria for home treatment in children (Koester project)

- age older than 1 year

- olid tumor or acute lymphoblastic leukemia in first remission

- availability of an indwelling central catheter (Hickmann)

- afebrile period of at least 24 hours prior to discharge

- favorable clinical evolution and improvement of the inflammatory tests

- adequate psycho-social environment

"Kinderkankerfonds, vzw". A prospective study is still ongoing concerning various aspects of this project.

\section{CONCLUSION}

Febrile neutropenia has undergone profound changes over the last decade. A subgroup of low-risk patients can be delineated that is amenable to out-of-hospital treatment. OHPAT is widely used in other severe infectious conditions (such as endocarditis, osteomyelitis, HIV infection ...) and is already common practice in the pediatric setting of febrile neutropenia in our country. A few limiting factors, mostly of financial and organizing nature, prevent the spread of home parenteral antibiotherapy to adult cancer patients at large. However, OHPAT can widely be provided in the outpatient clinics.

\section{REFERENCES}

1. Bodey $\mathrm{G}$ et al. Quantitative relationships between circulating leukocytes and infection in patients with acute leukemia. Ann Intern Med 1966; 64:328-40.

2. Pizzo et al. Fever in the pediatric and young adult patient with cancer, a prospective study of 1001 episodes. Medicine 1982;61:153-65.

3. Pizzo P. Management of fever in patients with cancer and treatment-induced neutropenia. N Engl J Med 1993;328:1323-32.

4. Rucker R, Harrison G. Outpatient intravenous medications in the management of cystic fibrosis. Pediatrics 1974; 54:358-60.

5. Antoniskis et al. Feasibility of outpatient self-administration of parenteral antibiotics. West J Med 1978; 128:203-6.

6. Tice AD. Preface to outpatient parenteral antimicrobial therapy. Infect Dis Clin North Am 1998; 12:xi-xii.

7. Francioli $\mathrm{P}$ et al. Outpatient treatment of infective endocarditis. Clin Microbiol Infect 1998; 4 (Suppl. 3):47-55.

8. Rhem SJ. Outpatient intravenous antibiotic therapy for endocarditis. Infect Dis Clin North Am 1998; 12:879-901.

9. Graninger $\mathrm{W}$ et al. Management of serious staphylococcal infections in the outpatient setting. Drugs 1997; 54 (Suppl. 6):21-6.
10. Levy J. et al. Treatment of bone and joint infections: recommendations of a Belgian panel. Acta Orthop Belg 2000; 66:127-36.

11. Brown R. Outpatient parenteral antibiotic therapy in the management of community-acquired lower respiratory infections. Infect Dis Clin North Am 1998; 12:921-34.

12. Gunner Deery II H. Outpatient parenteral antibiotic therapy for skin and soft-tissue infections. Infect Dis Clin North Am 1998; 12:935-50.

13. Tice D, Strait K, Ramey R, Hoaglund P. Outpatient parenteral antimicrobial therapy for central nervous system infections. Clin Infect Dis 1999; 29:1394-99.

14. Lutz B, Reed Pitre B, Joan Landry R. Practical considerations of outpatient infusion therapy in the HIV arena. Infect Dis Clin North Am 1998; 12:951-61.

15. Kern WV, Cometta A, de Bock R, Langenaeken J, Paesmans M, Gaya H. Oral versus intravenous empirical antimicrobial therapy for fever in patients with granulocytopenia who are receiving cancer chemotherapy. N Engl J Med 1999; 341:312-8.

16. Freifeld A, Marchigiani D, Walsh T, et al. A double-blind comparison of empiric oral and intravenous antibiotic therapy for low-risk febrile patients with neutropenia during cancer chemotherapy. N Engl J Med 1999; 341:305-11.

17. Talcott J, Whalen A, Clark J, Rieker P, Finberg R. Home antibiotic therapy for low-risk cancer patients with fever and neutropenia: a pilot study of 30 patients based on a validated prediction rule. J Clin Oncol 1994; 12:107-14.

18. Rolston K. Outpatient management of fever in neutropenic patients. Current Opinion Inf Dis 1996; 9:407-10.

19. Rolston K. New trends in patient management: risk-based therapy for febrile patients with neutropenia. Clin Inf Dis 1999; 29:51521.

20. Ball L, Siddal S, van Saenen H. Teicoplanin in home therapy of the terminally ill child. Eur J Haematol 1993; 51(Suppl.54):147.

21. Malik I, Khan W, Karim M. Self-administered antibiotic therapy for chemotherapy-induced low-risk febrile neutropenia in patients with non-hematologic neoplasms. Clin Infect Dis 1994; 19:522-7.

22. Malik I et al. Feasibility of outpatient management of fever in cancer patients with low risk neutropenia: results of a prospective randomized trial. Am J Med 1995; 98:224-31.

23. Delporte J. Aspects pharmaco-économiques de l'antibiothérapie à l'hôpital. Rev Med Liège 1998;53:279-84.

24. Newland A, Ketley N. Non-inpatient parenteral antibiotic therapy in febrile adults. Eur J Haematol 1998; 60(Suppl 62):6-10.

25. Parker et al. Evaluation of the impact of non-inpatient IV antibiotic treatment for acute infections on the hospital, primary care services and the patient. J Antimicrob Chemother 1998; 42:373-80. 
26. Williams D. Home intravenous anti-infective therapy (HIVAT): do the benefits outweigh the risks? Drug Safety 1996; 1:1-7.

27. Martone $\mathrm{W}$ et al. Incidence and nature of endemic and epidemic nosocomial infections. In Bennett \& Brachman, Eds: Hospital Infections, ed. 3, Boston, Little Brown, 1992: pp577-96.

28. Vinen J. Intravenous antibiotic treatment outside the hospital: safety and health economic aspects. Rev Contemp Pharmacother 1995; 6:435-45.

29. Eron L. Intravenous antibiotic administration in outpatient settings. Infect Dis 1984; 14:4-11.

30. Hoffman-Terry M. Adverse effects of outpatient parenteral antibiotic therapy. Am J Med 1999; 106:44-9.

31. Freifeld A, Pizzo P. The outpatient management of febrile neutropenia in cancer patients. Oncology 1996; 10:599-612.

32. Talcott $J$ et al. The medical course of cancer patients with fever and neutropenia. Arch Intern Med 1988; 148:2581-88.

33. Talcott J. Outpatient management of febrile neutropenia: should we change the standard of care? The Oncologist 1997; 2:36573.

34. Davis D, Raebel M. Ambulatory management of chemotherapyinduced fever and neutropenia in adult cancer patients. Ann Pharmacother 1998; 32:1317-23.

35. Hughes $\mathrm{W}$ et al. Guidelines for the use of antimicrobial agents in neutropenic patients with unexplained fever. Clin Infect Dis 2002; 34:730-51.

36. Klastersky J et al. The Multinational Association for Supportive Care in Cancer risk index: a multinational scoring system for identifying low-risk febrile neutropenic cancer patients. J Clin Oncol 2000; 18:3038-51.

37. Klaassen RJ et al. "Low-risk" prediction rule for pediatric oncology patients presenting with fever and neutropenia. J Clin Oncol 2000; 18:1012-9.

38. Herrmann R, Trent M, Cooney J, Cannell P. Infections in patients managed at home during autologous stem cell transplan- tation for lymphoma and multiple myeloma. Bone Marrow Transplant 1999, 24:1213-7.

39. The EORTC International Antimicrobial Therapy Cooperative Group. Gram-positive bacteremia in granulocytopenic cancer patients. Eur J Cancer 1990; 26:569-74.

40. Andes D, Craig W. Pharmacokinetics and pharmacodynamics of outpatient intravenous antimicrobial therapy. Infect Dis Clin North Am 1998; 12:849-60.

41. Gilbert DN, Dworkin RJ, Raber SR, Leggett JE. Outpatient parenteral antimicrobial-drug therapy. N Engl J Med 1997; 337:829-38.

42. Ozer $\mathrm{H}$ et al. Update of recommendations for the use of hematopoietic colony-stimulating factors : evidence-based, clinical practice guidelines for the American Society of Clinical Oncology Growth Factors Expert Panel. J Clin Oncol 2000; 18:3558-85.

43. Nathwani D, Zambrowski JJ. Advisory group on Home-based and Outpatient Care (AdHOC): an international consensus statement on non-inpatient parenteral therapy. Clin Microbiol Infect 2000; 6:464-76.

44. Williams DN et al. Practice guidelines for community-based parenteral anti-infective therapy. Clin Infect Dis 1997; 25:787801.

45. van den Broek, $\mathrm{P}$ et al. Thuisbehandeling met intraveneuze antimicrobiële middelen: een beproefde werkwijze. ITS 1995, Nijmegen.

46. Haerkens $\mathrm{H}$ et al. Intraveneuze toediening van antimicrobiële geneesmiddelen thuis. Een vergelijking met ziekenhuisbehandeling. TNO Preventie en Gezondheid 1997, Leiden.

47. Quak et al. Richtlijnen voor intraveneuze toediening van antimicrobiële geneesmiddelen thuis. TNO Preventie en Gezondheid 1997, Leiden. 